\title{
El fracaso de la autarquía: la política económica española y la posguerra mundial (1945-1959)
}

\author{
ANTONIO GÓmEZ MENDOZA*
}

\begin{abstract}
RESUMEN
El propósito de este artículo es mostrar que los miseros resultados económicos cosechados a fines del decenio de 1940 respondieron a la politica gubernamental y no, como se pretendió en la época, a la guerra mundial y al aislamiento diplomático.

A partir de 1951, la situación económica mejoró de forma significativa. En ambos períodos, fue fundamental el papel jugado por Juan A. Suanzes. En el primero, acumuló un enorme poder que le permitió controlar todos los ámbitos de la vida económica, puesto que compatibilizó

su cargo de ministro de Industria y Comercio con la presidencia del INI. Bajo presión de los Estados Unidos, Franco aceptó sustituir a Suanzes por ministros que propiciaron una cierta
\end{abstract}

ABSTRACT

It is shown in this paper that economic policy was responsible for the modest economic performance of the late 1940 's. Indeed, the impact of the second world war and the diplomatic isolation inflicted upon the Francoist regime by the Allies must be rejected. From 1951 onwards, the performance of the Spanish economy improved significantly. In both periods of time, the role played by Juan A. Suanzes was crucial. After 1945, every single field of economic policy was under his control since his appointment as Minister of Industry and Commerce was compatible with the chairmanship of a public industrial holding (INI). Under intense diplomatic pressure from the US Government, Franco was finally forced to withdraw Suanzes from the

* Universidad Complutense de Madrid.

Agradezco las observaciones de E. San Román a una primera versión de este trabajo que se ha enriquecido además con los comentarios de los asistentes a la reunión celebrada en el Istituto Italiano di Cultura en el otoño de 1994. Este trabajo ha sido realizado en el marco del proyecto PB93-0080 financiado por la DGICYT. 
liberalización de la política económica. Sin embargo, se trató de una reforma parcial abocada al fracaso.

PALABRAS CLAVE España. Italia. Franquismo. Autarquía. cabinet in 1951. Newly appointed ministers favoured the implementation of a slightly liberal economic policy which led, however, to failure.

KEY WORDS

Second World War. Spain. Italy. Francoism. Autarchy.

La victoria de los aliados no significó la derrota de las directrices autárquicas presentes en la política económica española en 1945. Ni el temor a la imposición de sanciones por parte de los aliados ni el hecho de que España fuera asimilada en la planificación comercial norteamericana a los países derrotados en la contienda mundial, hicieron concebir la más mínima esperanza de cambio en la actitud de los gobernantes españoles. Antes bien, la política aliada hacia España exacerbó el tono de unas soflamas que denunciaron un pretendido espíritu anti-democrático por negarle al régimen español el derecho a vivir de acuerdo con sus valores espirituales. Con una insistencia machacona, el régimen del general Franco perpetuó la línea de actuación desplegada a partir de 1938 lo que significó, a la postre, su auto-exclusión de los programas de ayuda internacional. Al reiterar una y otra vez el derecho a comprar en los mercados internacionales, las autoridades españolas no quisieron entender que esa capacidad dependía, en última instancia, de la libertad de los demás a venderles.

Las páginas que siguen, se ciñen al periodo 1945 a 1959. En esta segunda fecha, quedó enterrado de forma definitiva lo que se ha bautizado en la historiografía como la "autarquía bélica" ". Argumentaré que semejante orientación económica fue decisiva para explicar la lentitud del crecimiento en el segundo lustro de los años 1940. A ese respecto, deberá rechazarse cualquier sugerencia que vincule la moderación de los resultados cosechados en aquellos años con las circunstancias internacionales de la posguerra. Por el contrario, la expansión subsiguiente experimentada en la primera mitad del decenio de 1950 vino propiciada por un cambio en el ambiente económico que se concretó en dos manifestaciones principales. Como condición necesaria, resultó decisiva la exclusión de Juan A. Suanzes que había sido uno de los defensores más acérrimos de aplicar

Acerca de la política económica de este periodo, pueden consultarse, entre otros, Clavera (1973); Esteban (1977); Garcia Delgado (1986; 1987) y Viñas (1984). 
una política de corte autárquico entre 1938 y 1951 . Su salida del gobierno propició la entrada de personas que trajeron un aire fresco a la política económica en casi todos sus facetas, pues en lo industrial apenas si se notó hasta 1957.

El artículo está dividido en tres apartados. En el primero, establezco que el crecimiento de la economia española tuvo distinta intensidad en dos períodos sucesivos: 1945/49 y 1951/55. A continuación, examino las consecuencias de la perpetuación de una política de intervención económica a ultranza más allá de los límites temporales marcados por la victoria aliada. Su relajación, ocurrida de forma esporádica entre 1947 y 1948, se convirtió en un espejismo dentro de una orgía de intervencionismo cuyo principal objetivo fue apisonar a la empresa privada. En realidad, se trató de comportamientos oportunistas con la intención de aplacar la enemistad de los gobiernos aliados. En el último apartado, mostraré que la resistencia del régimen a abandonar sus viejas coordenadas económicas condujo a una situación singular en la que se simultanearon dos políticas antagónicas: una, autárquica, y otra con ribetes liberalizadores. Se desencadenó así un conflicto que culminó en una recesión en 1956. Significó el fracaso definitivo del modelo autárquico, dando paso a una liberalización de la economía española en 1959.

\section{CLAROS Y SOMBRAS EN LA RECONSTRUCCION (1945/1959)}

En el conjunto del período 1945/59, el PIB español creció a una tasa del 4,4 por 100. Tras ese resultado moderadamente satisfactorio que colocó el crecimiento en términos per cápita en torno a un 3,6 por 100 , se escondieron dos realidades bien distintas ${ }^{2}$. Por un lado, una realidad desoladora entre 1945 y 1949, años en los que se alcanzó una tasa mucho más lenta, con el agravante de que por dos veces (1947 y 1948) se registraron retrocesos. Aún así, el saldo del periodo fue significativo si lo comparamos con el estancamiento (0,3 por 100) experimentado en el quinquenio inmediatamente anterior. En particular, hay que destacar el fuerte retroceso de casi ocho puntos en 1944/45. Por otro lado, las cifras globales esconden una realidad mucho más esperanzadora que se manifestó en el transcurso de los años 1950. De hecho, en el bienio 1950/51, el crecimiento fue espectacular, lográndose una tasa de un 9,1 por 100. A partir de ese año, la expansión se consolidó hasta 1956 con una tasa media de

Carreras (1989), Cuadros 13.6 a 13.9 págs. 554/59; González (1979) cuadro II-3 pág. 44. 
un 5,7 por 100 . No obstante, la tendencia se quebró bruscamente en ese año al registrarse una fuerte desactivación.

Una segunda característica del período aquí considerado fue la transformación estructural de la economía española. A resultas de la mayor expansión macroeconómica recién descrita, dichos cambios se acentuaron a partir de 1950. En efecto, en el decenio anterior, la participación del sector primario habia permanecido anclada en torno a un 30 por 100 del PIB. En contraste, los avances fueron notables en 1960, reduciéndose el anterior porcentaje a menos de un 24 por 100 . En el mismo lapso de tiempo, la participación del sector secundario ganó casi diez puntos situándose en un 36 por 100 frente al 26 por 100 que apenas alcanzó en 1940.

Queda clara pues la existencia de dos subperiodos contrapuestos: 1945/49 y 1950/55. La moderación del crecimiento en el primero obliga a asimilarlo con la larga etapa plagada de dificultades que comenzó con la Guerra Civil. En acertada descripción, Albert Carreras la definió como la "noche de la industrialización" española, achacándole la responsabilidad de ampliar la brecha con respecto a los países de nuestro entorno ${ }^{3}$.

Para evaluar la magnitud del fiasco español en 1945/49, nada mejor que establecer una comparación con Italia. Frente a un aumento de un 30 por 100 en el índice italiano de producción industrial, el índice español progresó a una tasa diez veces más pequeña. Tan notable diferencia permitió a Italia recuperar en sólo diez años (1950) el techo de producción que había alcanzado en la preguerra. Por su parte, la economía española que no supo remedar el milagro de su vecino, invirtió nada menos que veintidos años (1952) ${ }^{4}$.

Tras la depresión, los años 1950 se convirtieron en un decenio «bisagra», en atinada descripción del profesor García Delgado, anunciando el cambio que habría de operarse con el Plan de Estabilización de 19595. Como nota sobresaliente, el decenio exhibió un tercer rasgo que se añadió a los dos ya comentados, es decir al fuerte crecimiento y profundidad del cambio estructural. Me refiero a un cambio de orientación en la política comercial aunque quizá describirlo como simple retoque fuera más apropiado. Desde una perspectiva de historia comparada, la economía española se aproximó en esta ocasión a la pauta europea si bien no logró recuperar las pérdidas que arrastraba desde el período anterior.

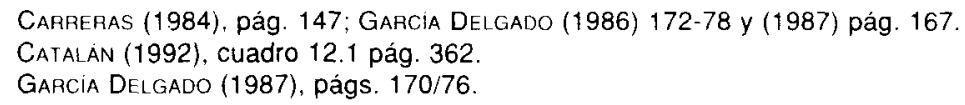




\section{LOS COSTES DE LA POLITICA AUTARQUICA}

De las cifras macroeconómicas manejadas más arriba, hemos extraído una primera conclusión: 1945/49 contiene las claves del atraso relativo de la economía española en el período contemporáneo. Por esa razón, las realizaciones materiales de Italia en el mismo plazo adquieren una significación especial. Permiten evaluar, en preferencia a cualquier otro indicador, los costes que entraño la obcecación del régimen franquista por mantener, contra viento y marea, una política basada en parámetros de autarquía económica. En efecto, lo ocurrido en Italia puede ilustrar sobre lo que habría conseguido España en el caso hipotético de haber optado por una política económica de distinto cuño.

Como es bien conocido, lo más destacable del período en el plano internacional fue el aislamiento que sufrió el régimen de Franco a manos de las potencias aliadas ${ }^{6}$. Para sus panegeristas, el cerco internacional decretado por Naciones Unidas en 1946 perjudicó a la coyuntura económica interior y, por ende, impidió que tuvieran éxito los esfuerzos emprendidos en pos de una industrialización forzada por el Estado. De ahí que una de las cantinelas más repetidas en la época, fuera la de achacar los malos resultados del período a la imposibilidad de acceder a los fondos del Programa de Recuperación Europea. Por el contrario, Italia recibió una sustancial ayuda exterior que, bajo la forma de créditos y donaciones, totalizó unos dos mil milllones de dólares entre 1945 y 1952 , el equivalente a un 3,5 por 100 de su renta nacional. Semejante volumen de recursos permitió equilibrar el déficit por cuenta corriente. Vista la experiencia italiana, se podría argüir que había un fondo de razón en el argumento anterior. Se llegaría entonces a la conclusión de que la recuperación española habría sido más rápida si se hubiera beneficiado de una ayuda exterior en idéntica cuantía a la italiana.

Sin embargo, la concesión de ayuda por parte de los gobiernos aliados estaba reñida con los fundamentos del sistema político español y con sus planteamientos económicos. Resulta tan inverosimil sugerir que el régimen habría renunciado a su programa autárquico en plena fase de supervivencia como aceptar que una política económica de corte liberal hubiese sido adoptada en 1939. En uno y otro momento desempeñó un papel decisivo el influyente ministro de Industria y Comercio, Don Juan A. Suanzes. Su entrada en el sexto gobierno constituido por el general Franco en el verano de 1945 se convirtió en un factor clave para entender el desarrollo

PORTERO (1989) págs. 137 en adelante. 
subsiguiente de la economía en el período 1945/51. El nombramiento encumbró a las más altas esferas del poder económico a quién fue precisamente uno de los artífices de la política autárquica que emprendió el Nuevo Estado en vísperas de la segunda guerra mundial ${ }^{7}$. Al ocupar la cartera de Industria y Comercio sin abandonar por ello la presidencia del Instituto Nacional de Industria (INI), Suanzes detentó todos los resortes del poder comercial e industrial. Controló incluso la decisiva Dirección General de Política Económica que, por estar encuadrada en el organigrama del ministerio de Asuntos Exteriores, administró al alimón con su titular, Alberto Martín Artajo. De esta forma, Suanzes hizo realidad uno de sus más ardientes anhelos sobre el que había hecho descansar el éxito del programa autárquico a aplicar en España: i.e., centralizar el mando económico con objeto de evitar duplicaciones innecesarias. En el pasado, había lamentado que la cadena de decisión estuviera descentralizada, pues «en toda la [función] económica no existe la unidad de acción y mando que debería estimarse absolutamente indispensable" ${ }^{8}$.

Libre pues de las interferencias incómodas que le deparó reiteradamente entre 1941 y 1945 Demetrio Carceller, su predecesor en la cartera de Industria y Comercio, Suanzes se enfrentó con ahínco a la doble tarea de, por un lado, dar forma al "engrandecimiento» industrial del país, lo que habría de plasmarse en una regeneración forzada por el Estado a través del INI y, por otro, de nivelar la balanza comercial. En pos de uno y otro objetivo, se declaró partidario de acometer una intervención contundente en la economía, sometiendo al sector privado al dictado del Estado en razón de la capacidad de éste último para atajar injerencias indeseadas procedentes del extranjero.

Pocos de los objetivos que se marcaron en los planes de autarquía en 1939 habían sido cubiertos. Por lo que atañe a la nivelación de la balanza comercial, el éxito fue parcial pues se consiguió sólo en dos ocasiones, 1943 y 1945. Tras una mejora sustancial entre 1940 y 1942, la relación de intercambio empeoró notablemente en los tres años siguientes. En cuanto a la directriz del plan autárquico que perseguía una nacionalización de una serie de industrias controladas por el capital extranjero, al que se imputó el propósito descarado de torpedear los esfuerzos acometidos por el gobierno para salir del subdesarrollo, aquí el fracaso fue rotundo a excepción de lo ocurrido en el sector de las comunicaciones ferroviarias y telefónicas. A pesar de las condiciones excepcionalmente halagüeñas que 
creó la coyuntura bélica para estos propósitos, ni se asumió el control de los mercados de aquellas materias primas en los que el país gozaba de la ventaja de partida de tener las mayores reservas del mundo ni se nacionalizaron las compañías 'coloniales' más emblemáticas ${ }^{9}$. La prospección del subsuelo, otro objetivo de la autarquía, no permitió tampoco descubrir yacimientos de importancia ni alcanzar una ansiada autosuficiencia en materia energética ${ }^{10}$. La pesada maquinaria del INI tardó en ponerse en movimiento, agobiada por una elevada dependencia técnica respecto del extranjero, rasgo que empeoró con la derrota alemana. Con patentes nacionales, el engrandecimiento industrial quedó circunscrito a una economía de la miseria, a un uso extensivo de sucedáneos y a un aprovechamiento de residuos.

Así pues Suanzes concibió su nombramiento como una oportunidad personal de impulsar la consecución de los fines propuestos en la política de reconstrucción, fines que se basaban en unos planes de autarquía que trazó él mismo al término de la guerra civil ${ }^{11}$. Por esa razón, desplegó inmediatamente una política acorde con la orientación básica de la autarquia, es decir fomentar la industria y nivelar la balanza comercial, multiplicando para ello los instrumentos de regulación e intervención entre 1945 y 1947. El margen de maniobra del que dispuso, se vió seriamente constreñido por el mantenimiento a ultranza de un tipo de cambio para la peseta, elegido en el pasado con unos criterios políticos que no respondían en absoluto a la realidad del momento. La negativa a aceptar una devaluación de la peseta respondió a una falsa razón de prestigio nacional y a la terquedad personal de Franco, aspecto en el que fue respaldado plenamente por su ministro ${ }^{12}$. Los costes de esa política cambiaria quedaron rápidamente al descubierto. Una vez que la desmovilización disparó los precios interiores en los países europeos y se consumó la depreciación de sus divisas, las consecuencias fueron inmediatas: frenazo en seco de la exportación española que ya en 1947 se situó 18 puntos por debajo de la cota alcanzada en 1945, mientras que la demanda de importaciones rebasó en un 53 por 100 ese nivel ${ }^{13}$. Por supuesto, aquella progresión ascendente de las importaciones entró en contradicción con la tesis oficial según la cual el aislamiento político exterior, materializado en el cierre de la frontera francesa y en la retirada de embajadores, era un obstáculo para

Gomez Mendoza (1994).

Gomez Mendoza (1995).

Gomez Mendoza (1994a)

tbidem. págs. 356-57.

TENA (1989), cuadro 8.4 págs. $346-47$ 
los intercambios. En realidad, el problema fue totalmente distinto. Radicó en la incapacidad española para aumentar el excedente exportable al tiempo que el desastre agrícola obligó a destinar los escuetos saldos en divisas a la compra de alimentos. Es significativo señalar que las importaciones alimentarias representaron un 25 por 100 de la importación total en 1949. Por lo demás, esa evolución del comercio se produjo a pesar de la aplicación de un sinfín de regulaciones comerciales cuya finalidad era evitar lo inevitable: es decir, erradicar un persistente déficit por cuenta corriente que acabó horadando cualquier perspectiva futura de progreso para la economía española. En efecto, el déficit comercial se disparó entre 1946 y 1949 tan pronto se esfumaron las circunstancias excepcionales que había creado la guerra mundial. Quedaron reducidas en consecuencia las reservas de divisas y de oro lo que, a su vez, comprometió la viabilidad de las políticas de reequipamiento industrial así como la compra de materias primas imprescindibles para suplir la escasa oferta doméstica.

La salida al impasse en que se colocó a sí mismo el régimen al persistir en una política de intervención a ultranza, en una política de sometimiento del sector privado a la férula del Estado y en una política de alejamiento respecto de las prácticas de mercado, se produjo por dos vías complementarias: diplomática y de política económica.

En el ámbito diplomático, fueron de destacar los esfuerzos desplegados para canjearse una valiosísima ayuda alimentaria por parte de la Argentina de Perón a mediados de 1946 y para obtener un crédito norteamericano con un elevado contenido simbólico a comienzos de 1949. En efecto, Martín-Artajo y Suanzes se volcaron a partir de 1947 para intentar el desbloqueo de la política exterior del régimen con la meta final de acceder a los fondos del European Recovery Program, la ruptura del aislamiento con la vuelta de los embajadores así como la integración de España en los planes occidentales de defensa. Apelaron, por un lado, a la formación de grupos de presión en Estados Unidos e Inglaterra a los que encargaron la tarea de potenciar ante las tribunas públicas de esos paises el valor estratégico de la Península y la faceta anticomunista de las autoridades españolas ${ }^{14}$. Apelaron igualmente a los buenos oficios de intermediarios tan poco sospechosos de connivencia con el régimen como lo fue una multinacional minera inglesa o banqueros españoles de gran renombre en los medios financieros anglosajones como don Andrés Moreno, a la sazón consejero delegado del Banco Hispano-Americano ${ }^{15}$. Por otro lado, Martín- 
Artajo y Suanzes acometieron un estrategia de maquillaje con el propósito de convencer a los políticos y a los potenciales inversores norteamericanos de que el régimen estaba dispuesto a suavizar su postura en los temas conflictivos que se le había indicado; es decir, (a) el tipo de cambio; (b) el parapeto proteccionista edificado en torno al mercado interior; (c) el trato dispensado a los empresarios privados y (d) la situación de las empresas extranjeras con intereses en España, aspecto que fue suscitado en alusión directa al caso de la Barcelona Traction. Franco instó a sus dos ministros a conseguir los fines marcados a cualquier coste. Para ello, Martín-Artajo y Suanzes dieron innumerables muestras de una tímida y poco convincente voluntad de evitar conflictos innecesarios con las potencias aliadas. Un ejemplo del nuevo talante fue la condonación de una multa por el fraude fiscal en que había incurrido una gran empresa minera británica que operaba en el suroeste español. En condiciones normales, aquella multa habria supuesto la pérdida de los títulos de propiedad que detentaba sobre los yacimientos piríticos más famosos del mundo ${ }^{16}$. Con ésta y similares pruebas, los dos ministros intentaron a la desesperada hacer olvidar los pecados anteriores y lavar una imagen que ya estaba excesivamente maltrecha.

Por lo que atañe a la política económica, se consumó un cambio de barniz, sin renuncia a los principios fundamentales del ideario autáquico nacionalista. Merece destacarse, primero, una suavización de la actitud que dispensó Suanzes a la empresa privada. Con ello inauguró un clima de concordia y entendimiento con el sector privado en busca de una cooperación que, por lo general, no consiguió para los grandes proyectos industriales emprendidos por el INI en esos años en ámbitos diversos; por citar un par de ejemplos, el establecimiento de una siderurgia integral (ENSIDESA) o la formación de una red de frigoríficos ${ }^{17}$. En lo que significó un distanciamiento respecto de los planteamientos anteriores, Suanzes declaró en 1948 que el INI era un:

"organismo concebido como una complementación de la iniciativa privada en el orden industrial apoyando el espíritu particular de empresa cuando se repute útil hasta dónde aquélla no llegue, supliéndolo cuando sea insuficiente y promoviendo actividades o de demasiada monta para los sectores privados exclusivamente o inciertos en su rendimiento y arriesgados en su rentabilidad bien que necesarios al acervo económico nacional»,

al tiempo que precisaba que el gobierno era:

GoMez Mendoza (1994), págs. 249/59.

GOMEz MENDOZa (1995a). 
«intervencionista exclusivamente en el grado preciso para garantizar una necesidad o un superior interés nacional, un orden relativo a la defensa del débil contra el fuerte" ${ }^{18}$.

En consonancia con esas declaraciones, Suanzes preparó una nota para responder a las críticas que le fueron planteadas por los negociadores norteamericanos (véase más adelante). Amén de proclamar el anhelo del régimen en conseguir una mejora de las condiciones de vida materiales y espirituales de los españoles, reiteró que:

"el Estado reconoce el inmenso e insustituible valor de la iniciativa privada, fuente inigualada de progreso" ${ }^{19}$.

Contempló incluso la posibilidad de abordar una cooperación con el capital extranjero. Falto de liquidez, el régimen necesitaba atraer por cuantos medios estuvieran a su alcance, inversiones extranjeras y, en particular, las procedentes de los Estados Unidos. En reuniones mantenidas con banqueros y empresarios de ese país en 1947, Suanzes había insistido en la aspiración general de lograr una «eficaz cooperación en actividades de producción y transformación». Para combatir el recelo que los inversores extranjeros mostraban hacia la política española de nacionalizaciones, Suanzes empleó argumentos futiles. Aquéllas afirmó el ministro al tiempo que presidente del INI,

“se efectúan por mutuo acuerdo y sin lastimar legítimos intereses».

Con ese tipo de afirmaciones, intentó quitar hierro a la preocupación que despertaba el límite legal de un 25 por 100 del capital social en las empresas coparticipadas por extranjeros. Dejó entrever la posibilidad de que esa cuota podria ser anulada mediante subterfugios aceptables para ambas partes. En unas declaraciones al diario Arriba realizadas en 1948, reiteró su llamamiento a los inversores extranjeros en los términos siguientes:

"Las aportaciones de técnica o de capital extranjero para potenciar nuestra industria o nuestra economía en general son, no sólo perfectamente recibidas, sino estimuladas o deseadas" ${ }^{20}$.

18 SuANZES (1948), págs. 5 y 19

"Nota sobre orientaciones de la política económica. Confidencial y personal» (10-3-1949), Archivo Suanzes R. 444.

20 Ibidem, pág. 34. 
En el plano estrictamente comercial, aquel giro en las formas se plasmó en la renuncia parcial a uno de los fundamentos más queridos de la política económica del régimen. En la política cambiaria, otrora considerada intocable, Suanzes instauró a finales de 1948 un peregrino sistema de cambios múltiples en un tardío intento por incentivar la exportación a la par que frenar la importación de artículos menos necesarios ${ }^{21}$. Sin embargo, al quedar las bonificaciones concedidas a los exportadores muy por debajo de la devaluación de las monedas de los principales clientes de España, el nuevo sistema apenas si tuvo una repercusión efectiva. En la práctica, exacerbó el confusionismo y la arbitrariedad, introduciendo una discriminación entre importadores y exportadores, entre unas mercancías y otras $e$ incluso entre mercancias de distintas calidades. Al acudir a un parche tan burdo, el régimen volvió a dar una muestra de su miopía en materia económica, ya que una devaluación a secas de la peseta habría servido para reactivar la exportación aunque sin duda hubiera acentuado aún más la inflación subyacente. Por el contrario, los competidores más cercanos de los productos españoles sí accedieron a modificar de forma sustancial su cambio oficial. A este respecto, recordemos que la lira que se cotizaba a cien unidades por dólar en 1945 pasó a 625 cinco años más tarde.

Es de advertir que tan pronto se consolidó la rehabilitación del régimen franquista en el exterior y se suavizaron los apremios económicos más perentorios en el interior, se reinició un viraje hacia la normalidad, entendiendo por tal el retorno de Suanzes por antiguos derroteros. El reconocimiento aliado azuzado por los comienzos de la Guerra Fría se materializó en la vuelta de embajadores, la consecución de acuerdos comerciales bilaterales con el Reino Unido y Francia y la admisión de España en organismos dependientes de la ONU. Por lo demás, un régimen de lluvias más regular y avances sustanciales logrados en la producción de fertilizantes nitrogenados permitieron mejorar la productividad agricola. La menor dependencia exterior en materia alimentaria abrió nuevas perspectivas de crecimiento porque liberó los saldos de moneda extranjera para el reequipamiento de la industria española y, de modo especial, del sector exportador.

En efecto, al amparo de varios acuerdos bilaterales concluidos en la primavera de 1948, de la cooperación técnica y financiera de varios países en los planes del INI (léase, por ejemplo, la participación de la FIAT en SEAT) amén de los progresos realizados en la posición internacional de España, Suanzes olvidó pronto las promesas conciliadoras que habia

VIÑAS et al (1978), I, págs. 575-90. 
hecho a empresarios privados españoles y extranjeros, retomando una actitud de beligerancia a su respecto ${ }^{22}$. Espoleado por su presidente-ministro, el INI irrumpió de nuevo en sectores de fuerte implantación privada con un afán desmedido por captar cuotas de mercado en su provecho ${ }^{23}$. Suanzes desempolvó viejas aspiraciones tales como plantar cara a los intereses extranjeros en España para forzar su salida del país o como revalorizar la exportación de materias primas y de productos intermedios por métodos extraeconómicos con vistas a mejorar los términos del intercambio. En uno y otro objetivo, recurrió a la aplicación de una nueva gama de instrumentos de intervención, regulación y coacción. Se demostró entonces claramente que la relajación ocurrida entre 1947 y 1949 no fue más que un espejismo. En efecto, las ideas del ministro sobre la conveniencia de captar capital extranjero retornaron rápidamente a una concepción marcadamente nacionalista, como lo prueba el siguiente pasaje:

"El capital extranjero minoritario debe ser atraído, bien recibido, cuídado y garantizado en todo lo posible; pero los mandos económicos, técnicos, orgánicos y administrativos deben estar siempre en manos y bajo responsabilidad española» ${ }^{24}$.

Por supuesto, aquel rebrote de beligerencia hacia la empresa privada, máxime cuando se trataba de empresas foráneas, no pasó desapercibido a los observadores extranjeros. Así se lo manifestaron en el otoño de 1949 los representantes del Departamento de Estado a los emisarios españoles destacados a Washington para negociar la concesión de un crédito por el EXIMBANK a España por un importe de 1.300 millones de dólares. Para Achilles que a la sazón dirigía la Oficina de Asuntos de la Europa Occidental, cualquier mejora de las relaciones comerciales entre los dos países exigía una reforma previa de la política económica española en aspectos reivindicados en el pasado como el tipo de cambio o el "excesivo" control sobre las importaciones y su distribución. En esta ocasión, las exigencias norteamericanas abarcaron a otras facetas como la «influencia del INI y su competencia con la empresa privada" y la restricción del 25 por 100 sobre las inversiones extranjeras ${ }^{25}$. La falta de voluntad por parte española para acceder a semejantes pretensiones fue determinante para

Para la negociación con la FIAT, véase San Román (1995)

El caso de la SEAT es paradigmático en este sentido. Suanzes arrebató a financieros es pañoles encuadrados en el BANCO URQUIJO el proyecto que habían concluido con la FIAT para establecer una industria automovilística en España. Véase San Román (1995).

24 Subrayado en el original. Suanzes (1952) pág. 25.

25 Department of State, "Memorandum of Conversation" (1-11-1949), Archivo Suanzes R. 516. 
que las autoridades americanas sólo autorizasen un crédito por un importe de 62,5 millones de dólares, lo que quedó muy lejos de los 1.300 millones solicitados.

En suma, puede afirmarse que las modificaciones introducidas en la política económica a partir de 1947 lo fueron mucho más en la forma que en el fondo, pues el régimen se resistió a enterrar los viejos ideales autarquizantes de intervención y de regulación extrema. Si los apartó de forma momentánea, lo hizo en un alarde de oportunismo político y económico obligado por las circunstancias del momento. La falta de convencimiento en las acciones propias se tradujo en una inevitable falta de respuesta: los resultados inmediatos fueran desastrosos. Controlados por Suanzes, los escasos saldos en divisas exacerbaron una distribución que resultó cada vez más lesiva a los intereses del sector privado ${ }^{26}$. Falta de nuevos equipos y de piezas de recambio para reemplazar unas instalaciones que habían quedado obsoletas, la industria española se afanó inútilmente por compensar a través de la productividad el aumento de las retribuciones salariales que las autoridades laborales decretaron en un intento a la desesperada por prevenir el colapso del poder adquisitivo de la población activa. El respiro que proporcionaron los cambios especiales y la mayor complacencia que demostraron las autoridades revisando al alza los precios de tasa, resultaron insuficientes para evitar un nuevo deterioro de los beneficios empresariales. Para colmo, el creciente desequilibrio entre oferta y demanda generó un rebrote de los precios, registrándose las mayores tasas de inflación de todo el decenio (18,1 por 100 en 1948 y 28,3 por 100 en 1950).

A pesar de tan adversa coyuntura, no faltaron elementos de optimismo. La suavización de las relaciones diplomáticas y, en particular, la vuelta de los embajadores, la actitud cada vez más favorable de los Estados Unidos hacia España, la repercusión de la Guerra de Corea en los mercados mundiales y por último, el aumento de la inversión pública propiciaron un cambio de las expectativas empresariales permitiendo que la inversión privada iniciase una lenta recuperación. En efecto, en términos de la renta nacional, la inversión aumentó desde un 11 por 100 en 1948 a un 18 por 100 diez años más tarde, convirtiéndose en uno de los motores de la reactivación que se operó en la primera mitad de los años $50^{27}$.

26 Azuzado por las autoridades norteamericanas, se vió obligado, no obstante, a transigir en lo tocante a la distribución del crédito del EXIMBANK, reservando una pequeña asignación a la empresa privada.

27 CarReras (1990), pág. 121. 


\section{LA DERROTA DE LA POLITICA AUTÁRQUICA}

La marcha de los acontecimientos dejó a las claras que la presencia de Suanzes al frente de la economía española era incompatible con cualquier veleidad liberalizadora que, con insistencia, era requerida desde el exterior. De ahí que, bajo presión norteamericana en las negociaciones iniciadas en 1951, Franco se viese obligado finalmente a sacrificar a Suanzes en una nueva remodelación de su gobierno. Sin embargo, más importante incluso que la exclusión del ministro, fue la decisión de segregar el Ministerio de Industria y Comercio en dos mitades autónomas. Al recaer la jefatura de la rama industrial en Planell que había sido fiel lugarteniente de Suanzes en el INI, se garantizó así la continuidad de una línea dura en temas de política industrial. En contraste, la llegada de don Manuel Arburúa a Comercio resultó decisiva para asentar los cimientos de una política comercial distinta que culminaría, ocho años más tarde, en el Plan de Estabilización. Con un talante nuevo y con apoyos en los círculos financieros más influyentes del país, Arburúa abordó de inmediato una renovación de la política comercial que centró sobre tres ejes principales: Primero, apostó por una economía menos encorsetada lo que exigió la quiebra del modelo autárquico anterior; segundo, respetó el juego de las fuerzas del mercado lo que significó el fin de la intervención obsesiva que había practicado Suanzes; y tercero, apoyó a la iniciativa privada en sustitución del estatismo a ultranza desarrollado hasta aquel momento ${ }^{28}$. La orientación propugnada por Arburúa en Comercio fue complementada por las acciones de Rafael Cabestany en Agricultura. Su preocupación por impulsar una modernización del sector primario y por intensificar la producción, permitió al fin desviar divisas hacia la adquisición de bienes de equipo.

Como ya indiqué en el primer apartado, el decenio de 1950 distó de constituir un todo homogéneo. El ciclo expansivo se detuvo bruscamente en 1957. Se puso entonces en evidencia un agotamiento del modelo de crecimiento iniciado seis años atrás. De nuevo, el talón de Aquiles de la economía española volvió a ser el sector exterior. En efecto, la fuerte expansión del primer lustro de los 50 impulsó un auge espectacular de la demanda de importación, lo que cercenó las reservas de divisas una vez agotada la ayuda norteamericana. El déficit comercial sólo quedó cubierto mientras duró la entrada de dólares que alentaron los pactos de Madrid del otoño de 1953. Con un mecanismo tan precario de equilibrio, la economía española estuvo pronto abocada a una situación de bancarrota. De

28 Esteban (1984), pág. 169; Gonzalez (1978). 
ahí que Franco hubiera de aceptar un giro de $180^{\circ}$ en la política económica de la mano de un equipo de gestores integrado por tecnócratas adscritos a la organización ultra católica del Opus Dei. Sin embargo, la pervivencia de Joaquín Planell como titular de la cartera de Industria no suscitó nuevos conflictos con los restantes ministerios económicos porque, al fin, se alineó abiertamente con las nuevas orientaciones. Su comportamiento denotó una ruptura de la larguísima vinculación que le había unido a Suanzes ${ }^{29}$. Acabó pues por distanciarse respecto de los planes de industrialización que abordó el INI porque siguieron anclados en concepciones que habian quedado obsoletas en los nuevos tiempos.

Las políticas desarrolladas por Arburúa y Cabestany permitieron intensificar los intercambios comerciales y modificar la composición de las importaciones. Frente a un 6,8 por 100 en los años 1940, el comercio exterior aumentó su participación en la renta nacional hasta un 8,7 por 100. Se trató de un aumento significativo, si bien los niveles fueron todavía excesivamente modestos. En cuanto a la composición de las importaciones, los alimentos perdieron entidad pasando de un 25 por 100 de la importación global en 1949 a un 11 por 100 en 1959. En ese mismo lapso de tiempo, los bienes de equipo ganaron siete puntos, situándose en torno a un 20 por $100^{30}$.

Sin embargo, la propia reactivación generó tensiones que acabaron por llevar a la economia española a un nuevo callejón, con una única salida. Aumentó de forma espectacular la importación, disparando la magnitud del déficit comercial a falta de una evolución acorde de las exportaciones. Estas últimas se hallaron constreñidas por los limites al crecimiento que imponian las numerosas rigideces internas así como por la dependencia respecto de factores de naturaleza no económica, tales como las condiciones climatológicas. Al coincidir en 1956 el fin de la ayuda americana con unas heladas que arruinaron la cosecha de cítricos, el déficit comercial absorbió la casi totalidad de las reservas de divisas, dejando a la economía en situación harto precaria. Lo más grave fue que el modelo autárquico de sustitución de importaciones mantenido por Suanzes en el INI con la complicidad de Planell en el ministerio, distó de dar frutos cuando falló uno de sus pilares fundamentales: la pretendida riqueza mineral del subsuelo español. La fe ideológica en la existencia de yacimientos de hidro-

La relación entre los dos personajes se remontaba a los comienzos de la aventura del INI cuando Planell recibió de manos de Suanzes la presidencia de la E.N. de Combustibles y Lubricantes "Calvo Sotelo".

30 TENA (1989), pág. 350 
carburos, de gas natural y de pirita ferrocobriza no bastó ${ }^{31}$. Se alcanzó entonces una situación paradójica. Los propios funcionarios del INI unieron sus voces a quienes, desde otros ámbitos de la economía española, venían reclamando desde hacía años un mayor grado de libertad para los intercambios interiores, en claro desacuerdo con la política de Suanzes. Se fraguó así una extraña alianza con los centros del poder financiero en apoyo del abandono de las prácticas autárquicas. Para atenuar el desequilibrio del mercado de capitales, un observador tan autorizado como el BANCO URQUIJO propugnó reajustar los tipos de interés, modificar los precios de tasa y reformar en profundidad el sistema fiscal y presupuestario. Llama la atención que agentes económicos tan variopintos como el URQUIJO, asociaciones de empresarios o empresas participadas por el propio INI comenzasen a emplear un lenguaje idéntico al coincidir en que

«no se trata de postular una libertad absoluta de mercado a la que se opondrían multitud de dificultades y que, si sana en principio, pudiera ocasionar un trauma de acomodación doloroso e incierto" ${ }^{32}$

A modo de conclusión, quiero resaltar que, en el marco de la recuperación económica europea de los años 1950, bastó la apertura de un simple portillo en el armazón ultranacionalista y ultraprotector de la economía española para que éste se resquebrajase con una relativa facilidad. La explicación a este hecho singular se halló en la falta de viabilidad de un modelo cuya única salida era su autodestrucción. En consonancia con esta última afirmación, quiero acabar estas páginas recordando unas palabras que el Profesor Manuel de Torres pronunció en 1956 al referirse a los obstáculos al desarrollo industrial español. Los calificó entonces como los propios de una

"situación autofágica, devoradora del desarrollo industrial mismo" ${ }^{33}$.

Situación que, en su opinión, respondía a la falta de coordinación de la política comercial e industrial así como a la falta de consistencia del proyecto industrial. Para corregir esa situación, abogó por una política de precios adecuada para estimular la inversión y por una legislación antimonopolística. 
En definitiva, abogó por una revisión profunda de los planteamientos económicos como única salida al callejón en que había colocado a España en 1957 la pervivencia de una autarquía económica.

\section{REFERENCIAS}

Banco URouijo (1954), La Economía Española 1952-1953, Madrid.

CARreras, A. (1989), “La renta y la riqueza" en Carreras (1989a), págs. 535-85.

- (ed) (1989a), Estadisticas Históricas de España (siglos Xix y XX), Madrid.

CARRERAS, A. (1990), “Gasto nacional bruto y formación de capital en España, 1849-1958: primer ensayo de estimación» en Carreras (1990a), págs. 113-138.

Carreras, A. (1990a), Industrialización Española: Estudios de Historia Cuantitativa, Madrid.

CATALAN, J. (1992), "Reconstrucción, politica económica y desarrollo industrial: tres economias del sur de Europa, 1944-1953" en Prados (1992), págs. 359-395.

Clavera, J. et al (1973), Capitalismo Español: De la Autarquia a la Estabilización (1939-1959), Madrid.

ESTEBAN, J. (1977), “La política económica del franquismo: una interpretación» en Preston (1977), págs. $147-180$

FontANA, J. (ed) (1986), España bajo el Franquismo, Barcelona.

GaRcia Delgado, J.L. (1986), "Estancamiento industrial e intervencionismo económico durante el primer franquismo» en Fontana (1986), págs. 170-191.

- (1987), "La industrialización y el desarrollo económico de España durante el franquismo" en Nadal (1987), págs. 164-189.

Gomez Mendoza, A. (1994), El "Gibraltar Económico". Franco y Riotinto, 1936-1954, Madrid.

- (1994a), "La economía española y la Segunda Guerra Mundial: un estado de la cuestión» en Tiempo, Espacio y Forma, Serie V, 7, págs. 349-69.

- (1995), "La cara oculta de la actuación del INI en la minería: piritas y potasas (1941/1963)» en Areas 16, págs. 195-212.

- (1995a), Hacia una Economia del Frio: el Plan de Red Frigorífica Nacional, 1947-1951, Facultad de CC.EE y EE Documento de Trabajo 9512.

GonzAlez, M.J. (1978), La Economía Politica del Franquismo (1940-1970). Dirigismo, Mercado y Planificación, Madrid.

Nadal, J. et al (eds) (1987), La Economía Española en el siglo xx. Una Perspectiva Histórica, Barcelona.

Portero, F. (1989), Franco Aislado. La Cuestión Española (1945-1950), Madrid

Prados, L. et al (1992), El Desarrollo Económico en la Europa del Sur: España e Italia en Perspectiva Histórica, Madrid.

Preston, P. (ed) (1977), España en Crisis: La Evolución y Decadencia del Régimen de Franco, Madrid.

SuANZES, J.A. (1938), "Conferencia pronunciada por el Ministro de Industria y Comercio con motivo del Primer Consejo Técnico de FET y de las JONS" (29-4-1938).

- (1948), La Industrialización de España, Madrid.

- (1952), La Industrialización, Obra Evidente y Preeminente del Régimen de Franco, Madrid.

TENA, A. (1989), “Comercio exterior» en Carreras (1989a), págs. 329-61.

ToRres, M. de (1956), Juicio de la Actual Política Económica Española, Madrid.

Vinas, A. et al (1978), Politica Comercial Exterior en España (1931-1975), Madrid, 2 vis.

Vinas, A. (1984), Guerra, Dinero, Dictadura. Ayuda Fascista y Autarquia en la España de Franco, Barcelona. 